\title{
Jóvenes cristianas por la justicia reproductiva: Defender el aborto frente a los fundamentalismos religiosos
}

\author{
Young Christian Women for Reproductive Justice: \\ Defending Abortion against Religious Fundamentalism
}

Fecha de recepción: 07/09/2021

Fecha de aceptación: 27/11/2021

Fecha de publicación: 07/03/2022

https://doi.org/10.48102/if.2022.v2.n1.200

\author{
Nadia Arellano Tapia* \\ narellanotapia@gmail.com \\ ORCID: https://orcid.org/0000-0002-7735-1963 \\ Licenciada en Desarrollo y Gestión Interculturales \\ Colectiva Las del Pozo, Red TEPALI y Colectivo Nos Hacen Falta \\ México
}

\author{
Andrea Yoselyn De Reza Jiménez** \\ andrisjmz@gmail.com \\ ORCID: https://orcid.org/0000-0001-5711-877X \\ Licenciada en Ciencia Política \\ Colectiva Las del Pozo \\ México
}

* Nadia Arellano Tapia estudió Desarrollo y Gestión Interculturales en la Facultad de Filosofía y Letras (FFyL) de la Universidad Nacional Autónoma de México (UNAM) y formó parte de la Escuela para Personas Jóvenes Defensoras de Derechos Humanos (EPJDDH) del CDH Vitoria. Actualmente es alumna del Programa de Estudios Críticos de Género y Teología de la Comunidad Teológica de México. Forma parte de la Red TEPALI y el Seminario de Intersecciones de lo Religioso (SEMIR); colabora con la asociación de Teólogas e Investigadoras Feministas de México. Acompaña a familiares de víctimas de violencia y trabaja con organizaciones de mujeres feministas creyentes y comunidades religiosas abiertas a la comunidad LGBTIQA+ en su movilización frente a los fundamentalismos religiosos.

** Andrea Yoselyn De Reza Jiménez es politóloga egresada de la Facultad de Ciencias Políticas y Sociales de la UNAM. Docente de la misma universidad; sus intereses académicos 


\author{
Gayatri Morales Fragoso*** \\ gayatrimoralesf@gmail.com \\ ORCID: https://orcid.org/0000-0002-5437-7730 \\ Licenciada en Literatura Dramática y Teatro \\ Colectiva Las del Pozo y Colectivo Jermú \\ México \\ Colectiva Las del Pozo**** \\ lasdelpozo@gmail.com \\ México
}

\title{
Resumen
}

En el presente texto compartimos nuestra experiencia como colectiva de jóvenes creyentes y feministas respecto a la defensa del derecho a decidir. Argumentamos que tomar en cuenta el papel de la religión en la configuración de las identidades de las mujeres y ampliar nuestros marcos de análisis respecto a su rol en el espacio público son procesos indispensables tanto para el fortalecimiento de nuestras acciones en defensa de la justicia reproductiva frente al avance de los fundamentalismos religiosos, como para la construcción de espacios de acompañamiento para las creyentes que viven procesos de aborto. Dividimos nuestros aportes en ejes temáticos que responden a tres necesidades que hemos identificado: 1) familiarizarnos con los discursos,

son: teología política, teología feminista, ecoteología, historia del cristianismo primitivo y contemporáneo y el medio ambiente.

*** Gayatri Morales Fragoso es dramaturga y escenógrafa egresada del Colegio de Literatura Dramática y Teatro de la FFyL (UNAM). Autora de dos libros de cuentos: Las visitas de Mamá Elvira y Cuentos para niños y niñas sobre la prevención del abuso infantil basados en leyendas Nähñu, publicados por el Instituto Nacional de los Pueblos Indígenas (INPI). Cofundadora y actual miembro del colectivo teatral feminista Colectivo Jermú, con quienes desde noviembre de 2020 ha presentado de manera virtual, vía WhatsApp y Telegram, la obra Menos mal que es torpe y que me quiere para diversos festivales y escuelas. Ha participado en múltiples ponencias y charlas, entre las que destacan el diálogo público sobre violencia digital junto a la activista Olimpia Coral Melo y la ponencia "Jermú: s. f. Mujeres que luchan y crean desde la rabia, el amor y el autocuidado". Ha colaborado en la coordinación de pastorales católicas juveniles y universitarias.

**** Somos una comunidad de mujeres jóvenes feministas de distintas tradiciones cristianas comprometidas con los derechos humanos, la justicia reproductiva, la laicidad del Estado y la dignidad de todas las personas. Creemos que las teologías feministas son una herramienta importante para hacerle frente al avance de los fundamentalismos religiosos en América Latina; apostamos por una fe liberadora porque confiamos en que el verdadero mensaje de Cristo siempre trae justicia y libertad. 
historia y forma de operar de las organizaciones fundamentalistas; 2) conocer algunos argumentos en defensa del derecho a decidir construidos desde la fe y visibilizar a las organizaciones de creyentes que defienden la justicia reproductiva a lo largo de América Latina, y 3) incluir en nuestras agendas de exigencia y movilización política la defensa de la laicidad y profundizar en el análisis de su papel en las sociedades contemporáneas.

\section{Palabras clave}

Aborto, feminismo, cristianismo, religión, fundamentalismos.

\section{Abstract}

In this text we share our experience as a collective of young believers and feminists in the defense of the right to decide. We argue that considering the role of religion in the configuration of women's identities and broadening our frameworks of analysis regarding its role in the public space are essential processes both for strengthening our actions in defense of reproductive justice in the face of the advance of religious fundamentalisms, as well as for the creation of spaces of accompaniment for believers who live through abortion processes. We divide our contributions in thematic lines that respond to three needs that we have identified: 1) to get acquainted with the discourses, history and way of operating of fundamentalist organizations; 2) to know some arguments in defense of the right to decide built from faith and to make visible the organizations of believers that defend reproductive justice throughout Latin America, and 3) to include in our agendas of demand and political mobilization the defense of secularism and to deepen the analysis of its role in contemporary societies.

\section{Keywords}

Abortion, feminism, Christianity, religion, fundamentalism.

\section{Introducción: ¿Quiénes somos Las del Pozo?}

Las del Pozo somos una colectiva de mujeres jóvenes y feministas provenientes de distintas tradiciones cristianas $^{1}$ que nos reunimos y acompañamos desde 2018. En ese entonces, la mayoría de nosotras cursábamos

1 Si bien aquí presentamos nuestra experiencia como mujeres jóvenes y cristianas provenientes de iglesias católicas y protestantes de distintas denominaciones, sabemos que 
los primeros semestres de distintas licenciaturas y, aunque proveníamos de contextos diferentes, compartíamos la experiencia de navegar una coyuntura histórica en la que nuestras identidades se veían profundamente confrontadas. Por un lado, como creyentes y participantes activas dentro de nuestras iglesias, vivimos muy de cerca el estallido de la llamada "lucha en contra de la ideología de género", que impactó el país y a nuestras propias comunidades de fe en el año $2016,{ }^{2}$ tras casi dos décadas de haber comenzado a gestarse discursiva y políticamente como respuesta a los avances en materia de derechos sexuales y reproductivos en organismos internacionales de derechos humanos (Ávila González, 2018; Mena López y Ramírez Aristizabal, 2018). A la par, como mujeres jóvenes, fuimos atravesadas también por las movilizaciones feministas que arrasaban en ese entonces el continente y denunciaban el orden patriarcal a través de movimientos como \#NiUnaMenos, \#MeToo, el Paro Internacional de Mujeres, las manifestaciones en contra de los feminicidios en México y la Marea Verde impulsada por las mujeres argentinas. Para nosotras era imposible no entender y empatizar con las denuncias que dichos movimientos posicionaban en la esfera pública, ya que podíamos interpretarlas a partir de las vivencias de nuestros propios cuerpos.

no existe una sola forma de ser creyentes y nuestras vivencias están marcadas por factores geográficos, económicos, étnicos, raciales, etarios. De igual manera, consideramos importante resaltar la necesidad de escuchar reflexiones y vivencias más allá del paradigma cristiano-católico-céntrico que impera en los países latinoamericanos. Sabemos que la pluralidad de expresiones religiosas en México y en el resto del mundo ha sido invisibilizada y estigmatizada de manera sistemática, y reconocemos que los propios conceptos que utilizamos a lo largo de este escrito ("religión" o "religiosidad", por ejemplo), en muchos casos, no dan cuenta de la diversidad espiritual que conforma esta región.

2 En México, éste fue el año que vio surgir las primeras movilizaciones multitudinarias convocadas por el Frente Nacional por la Familia y los pronunciamientos masivos por parte de iglesias evangélicas en contra de la "ideología de género" como respuesta a la iniciativa del entonces presidente Enrique Peña Nieto para homologar constitucionalmente las uniones entre personas del mismo sexo. En otros países, también se estaba viendo el alcance político y las nuevas formas de habitar el espacio público del conservadurismo religioso. En Colombia, por ejemplo, fue en ese año que la ciudadanía votó "no" a la firma de los acuerdos de paz entre el Gobierno y las Fuerzas Armadas Revolucionarias de Colombia (FARC), tras una campaña masiva de desinformación por parte de sectores conservadores respecto a la supuesta "infiltración del lobby gay para imponerse en todos los colegios" a través de dichos acuerdos. 
A lo largo de estos años acompañándonos, han sido muchas las discusiones y problemáticas de nuestro entorno que nos han hecho cuestionar nuestra fe, pero definitivamente el aborto ha sido una de las más complejas. ¿Y cómo no sería así, si posicionarse a favor del derecho a decidir implica confrontar una serie de mandatos, implantados en nosotras desde que nacimos, acerca de lo que significa ser mujer y, más aún, ser cristiana? Sostener un pañuelo verde implica poner en duda el orden simbólico que ha posicionado la maternidad como fin último en nuestras vidas -y que se refuerza dentro y fuera de nuestras iglesias a partir de la representación de María como modelo femenino a seguir: virgen y madre a la vez- para revelar la sexualidad como una parte integral de nuestras vidas -cuyo ejercicio va mucho más allá de la reproducción- y, a su vez, reivindicarnos a nosotras mismas como sujetas políticas con capacidad de tomar decisiones sobre nuestro propio cuerpo y futuro.

En nuestro intento por construir reflexiones colectivas que nos guiaran en medio de esta supuesta contradicción, fuimos encontrando voces disidentes que, desde hace años, se han levantado a lo largo de toda América Latina y el Caribe para cuestionar los discursos que, en nombre de la Divinidad, justifican la opresión y criminalización de las mujeres. Además de ello, comenzamos a escuchar y acompañar a amigas, familiares, compañeras e integrantes de nuestras iglesias ${ }^{3}$ que tomaron la decisión de interrumpir su embarazo. Conocer sus historias trajo consigo rupturas epistémicas en nosotras, puesto que "las que abortaban" dejaron de ser unas "otras" sin rostro y pasaron a ser mujeres que conocíamos, con historias de vida diversas, atravesadas por la clase, edad, racialización, etnicidad. Criminalizarlas implicaba poner el peso de una problemática social compleja, como lo son los embarazos no deseados, sobre sus hombros, reduciendo las razones que las llevaron a tomar esa decisión a "irresponsabilidad" o "degradación moral" y cerrando los ojos ante los riesgos físicos y emocionales que puede traer consigo terminar un embarazo en contextos de clandestinidad, falta

3 Es importante para nosotras enunciar que, a pesar de que a lo largo de este texto utilizamos el femenino, sabemos que no todas las personas que abortan son mujeres. Consideramos necesario seguir abriendo espacios para escuchar las vivencias de hombres trans y de personas no binarias con capacidad de gestar en torno a la salud sexual y reproductiva y reflexionar más respecto a cómo éstas se intersectan también con violencias relacionadas a la identidad religiosa. 
de redes de acompañamiento y de acceso a información actualizada y confiable para realizar el procedimiento de manera segura.

Cambiar de posicionamiento respecto al aborto también implicó rupturas con nuestros núcleos familiares y comunidades religiosas, así como procesos de transformación profunda de nuestra propia fe, casi en términos de lo que Garma (2018) denomina "conversión religiosa": no respecto a un cambio de adscripción (movilidad religiosa), sino como una nueva concepción de la realidad, de la narrativa vivida. Esto, además de impactar nuestra forma de relacionarnos con Dios, con las demás personas y con nosotras mismas, también desencadenó reconfiguraciones en nuestras formas de organización y práctica política.

Hoy en día, todas las que conformamos la colectiva nos asumimos como feministas y participamos en espacios de activismo con compañeras no creyentes. Además de respaldar procesos de aborto, algunas de nosotras nos hemos sumado a colectivos de acompañamiento a familiares de víctimas de violencia; otras hemos vinculado los análisis de género a nuestra labor académica y artística; otras ponemos el cuerpo para crear espacios seguros para personas LGBTIQA+ dentro y fuera de las iglesias y fortalecer la lucha por sus derechos. Si bien nuestras formaciones, aproximaciones teóricas y espacios de incidencia son diversos, todas reconocemos nuestro compromiso con los derechos humanos de todas las personas y la defensa del Estado laico.

El objetivo de este escrito es compartir algunos de nuestros aprendizajes, pues creemos que, hoy más que nunca, es indispensable para quienes abrazamos la lucha antipatriarcal repensar la manera en la que entendemos las identidades religiosas y su papel dentro del espacio público; no solamente para saber acompañar a las mujeres creyentes que viven procesos de aborto, sino también para hacerle frente a los discursos que, a través de una interpretación violenta de las Escrituras, buscan frenar el avance de nuestros derechos.

\section{¿Por qué tomar en cuenta la religión?}

Nuestro objetivo con este escrito no es difundir ningún tipo de discurso apologista respecto a la religión, pues estamos más que conscientes de las atrocidades que se han cometido en nombre de Dios y hemos experimentado en carne propia la violencia que se legitima a partir de los textos sagrados. No es un secreto que las Iglesias cristianas históricamente han sido 
aliadas fundamentales del sistema de dominación patriarcal y es entendible la desconfianza y, en muchos casos, la total aversión de muchas compañeras feministas cuando señalamos la necesidad de incluir la fe dentro de las conversaciones en torno al derecho a decidir.

A pesar de ello, no es posible ignorar que ésta forma parte de la identidad de la mayoría de las y los mexicanos. De acuerdo con el Censo de Población y Vivienda más reciente (Instituto Nacional de Estadística, Geografía e Informática [INEGI], 2020), 88.8\% de la población total y 90.1\% de las mujeres en nuestro país forman parte de alguna iglesia cristiana -católica o evangélica-. Como colectiva, creemos que seguir haciendo a un lado este tema nos ha impedido hablar de justicia reproductiva ${ }^{4}$ de una forma que se reconozca la diversidad religiosa como algo constitutivo de las sociedades contemporáneas y fundamental en la configuración de la identidad de las mujeres mexicanas, lo cual en muchos casos deja a las creyentes en un lugar vulnerable y confuso, sin acceso a información o a espacios seguros en los que podamos colectivamente reivindicarnos como sujetas de derechos.

Para muchas, las comunidades de fe son el principal espacio de participación y de interacción con otras mujeres. Es ahí donde reímos, lloramos, aprendemos, compartimos las tareas de cuidado, interpretamos lo que sentimos y construimos redes de apoyo. Renunciar a dichas comunidades no sólo implica rupturas a nivel personal sino también a nivel familiar y social.

Sentir que sus decisiones las obligarían a dejar atrás una parte de su identidad ha sido una constante en los testimonios que nos han compartido creyentes que viven procesos de aborto. Al interior de la mayor parte de las iglesias cristianas, el aborto es un tema que se trata desde afuera: se sugiere que no hay ninguna mujer en la comunidad que lo haya vivido $-\mathrm{y}$ si hubiera alguna seguramente estaría arrepentida y, en el mejor de los casos,

4 Nos parece importante resaltar las voces - sobre todo de mujeres racializadas - que han invitado a la construcción de un abordaje crítico respecto a la lucha por el derecho a decidir, al señalar su propensión a caer en prácticas y discursos racistas, clasistas y colonialistas (Davis, 2005, p. 236; Clansi, 2021). Frente a esto, varias activistas proponen que una perspectiva interseccional respecto al aborto implicaría hablar no sólo de éste, sino de justicia reproductiva de forma integral. Esto, en palabras de Valeria Angola (2021), implica "descentrarlo [el aborto] de la agenda y comenzar a ver las demás violencias que se ejercen hacia mujeres y personas gestantes" para garantizar "los derechos de quienes decidan interrumpir el embarazo, pero también de quienes deseen parir". 
dando testimonio de ello-. La forma en que se invisibiliza la situación provoca que muchas mujeres cristianas que deciden interrumpir su embarazo lo vivan en silencio y en soledad, sin poder acudir a la mayor red de apoyo que tienen y que llevan años construyendo, por temor a ser marginalizadas y juzgadas.

Por otro lado, muchas mujeres cristianas que toman esta decisión encuentran una gran dificultad para acercarse a organizaciones feministas en busca de acompañamiento, al considerarse "fuera de lugar" o creer que su fe podría ser cuestionada o menospreciada. Elina Vuola (2001) expresa su preocupación al respecto de la siguiente manera: "por mucho tiempo, el feminismo occidental ha situado a las religiosas [...] como desprovistas de agencia" y señala que "la perspectiva feminista debe cuidarse también de no juzgar la religión como opresiva en sí misma [...], sin escuchar las diferentes voces de las mujeres reales de todo el mundo" (p. 4).

Si acaso esto no resulta suficiente para considerar ampliar nuestros horizontes de reflexión al respecto de las identidades religiosas cuando planteamos el tema del aborto, mencionamos otro argumento que nos parece fundamental: las perspectivas reduccionistas respecto a la religión nos llevan a subestimar la capacidad de los sujetos creyentes de incidir políticamente en su realidad y, en consecuencia, nos impiden crear estrategias eficaces para hacerles frente cuando su actuar amenaza el acceso a los derechos y condiciones de igualdad para las y los integrantes de la sociedad.

La visión que por décadas guio el trabajo de los científicos sociales e investigadores del fenómeno religioso, visión que consideraba inminente su declive frente al avance de la racionalidad moderna basándose en la fórmula “a mayor modernización, mayor secularización" (de la Torre y Semán, 2021), ha probado ser incapaz de explicar las nuevas configuraciones de lo religioso en el espacio público, que hoy en día van más allá de los púlpitos para posicionar sus discursos mediante campañas en redes sociales, películas, libros, manifestaciones masivas, proyectos de ley; configuraciones que se articulan políticamente a través de organizaciones de la sociedad civil, asociaciones de profesionales de la salud y del derecho, comitivas de obispos o delegaciones de creyentes en organismos internacionales. Frente a este fenómeno, Nicolás Panotto (2019) afirma:

Quienes quedan aún más desorientados son sectores no religiosos

-desde el campo académico hasta el comunicacional y el propiamen- 
te político- que miran con sorpresa y hasta cierto espasmo el avance de los discursos religiosos en el espacio público. Al ver sus opiniones frente a ese fenómeno, podemos fácilmente darnos cuenta del origen de tal desconcierto: un gran desconocimiento del campo religioso y la evidencia de grandes prejuicios. Lo religioso se sigue percibiendo como un dominio de la vida privada, como una instancia totalmente alejada de la realidad social, sostenido en una profunda ignorancia del vasto y plural mundo religioso, con todas sus complejidades, tensiones y diversidad internas. (p. 13)

En esta discusión, la postura feminista que ha cuestionado el paradigma moderno que divide lo público y lo privado a través de la consigna de "lo personal es político" se hace más que relevante. José Casanova profundiza en esto al señalar que "restringir lo religioso al ámbito de lo privado tiene por intención despolitizar el campo, para circunscribir 'lo político' y 'lo público' en otras esferas donde lo personal, lo subjetivo, lo corporal, lo afectivo, quedan de lado" (en Panotto, 2019, p. 25).

\section{¿Quiénes son los fundamentalistas?}

La palabra fundamentalismo hoy en día se utiliza para definir un fenómeno que puede surgir en distintas tradiciones religiosas, caracterizado por "sistemas rígidos de creencias que se sustentan, a su vez, en textos revelados, definiciones dogmáticas y magisterios infalibles" (Tamayo, 2009, p. 74) que "ofrecen una visión dual del mundo y la realidad, haciendo una dicotomía entre bien y mal, creyentes e infieles" y "postulan la recuperación de lo religioso a través de la reconstrucción de la tradición y de un 'orden sagrado' frente a las tendencias modernizadoras y secularizadoras" (Caro y Fediakova, 2000, p. 455). Sin embargo, el término tiene su origen en un contexto muy concreto: el protestantismo evangélico estadounidense de principios del siglo XX.

Su uso se remonta a la publicación de The Fundamentals: A Testimony to Truth, doce fascículos distribuidos en iglesias entre 1910 y 1915 con el objetivo de "defender los puntos fundamentales de la fe cristiana amenazados por la exégesis moderna y el liberalismo que habían entrado en la teología" (Tamayo, 2009, p. 75). Este movimiento, cuyo énfasis estaba colocado únicamente en un inicio en la defensa de la sacralidad de la escritura, empezó a evolucionar poco a poco frente al avance de las 
nuevas corrientes metodológicas y de interpretación teológica progresistas de aquel entonces y la ridiculización que vivieron por parte de los medios de comunicación tras escándalos como el conocido "Juicio de Scopes". ${ }^{5}$ Para los años cincuenta, el movimiento fundamentalista empezó a dejar atrás su oposición a las ciencias, la filosofía y el intelectualismo para abrazarlas como herramientas en su "defensa de la fe y moralidad cristianas". En los setenta, también se cimentaría su participación en la política con el apoyo a los candidatos republicanos Ronald Reagan y George Bush, con lo que "rompían el aislamiento político en el que se encontraban y colocaban la supuesta 'mayoría moral'b al servicio de una política ultraconservadora" (Tamayo, 2009, p. 78).

Pronto, los movimientos fundamentalistas consolidaron la estrategia de utilizar argumentos teológicos acerca de la inmoralidad y el pecado dentro de las iglesias y, al mismo tiempo, retomar discursos científicos, jurídicos y filosóficos, que complementaban su visión teológica, fuera de los espacios religiosos -denominada por Juan Carlos Vaggione (2005) como "secularismo estratégico"-, así como la formación de alianzas políticas para impulsar agendas conservadoras. Estas estrategias hoy en día se mantienen y articulan en la llamada "lucha en contra de la ideología de género", la cual busca oponerse a los avances legales en materia de derechos sexuales y reproductivos y es financiada por los grandes aportes económicos de políticos de derecha a lo largo del continente americano (Mena López y Ramírez Aristizabal, 2018, p. 26).

5 The Scopes Monkey Trial (1925) fue un proceso jurídico en contra de John T. Scopes, profesor de biología de una preparatoria pública, quien decidió enseñar a sus alumnos la teoría de la evolución de las especies, yendo así en contra del relato bíblico de la creación y de la ley del Estado de Tenessee. El proceso fue muy publicitado y, a pesar de que concluyó con Scopes declarado culpable y forzado a pagar una multa, el movimiento fundamentalista que lo acusó quedó ampliamente desacreditado y caricaturizado (Tamayo, 2009, p. 76).

6 The Moral Majority (1979) fue una organización conformada por evangélicos conservadores que querían involucrarse en el proceso político con el fin de preservar "valores familiares tradicionales"; se mostraron en contra de la igualdad entre hombres y mujeres, de los derechos de homosexuales y lesbianas, el aborto, el feminismo, el divorcio y la libertad religiosa. Se priorizó una agenda nacionalista y de derecha republicana. Utilizaron las telepredicaciones como forma de difundir su propaganda y recaudar fondos (Pérez Cruz, 2017, p. 192). 
Esta nueva ola de los fundamentalismos ${ }^{7}$ agrupa estratégicamente diferentes movimientos feministas y de la diversidad sexo-genérica, así como derechos sexuales y reproductivos, dentro del concepto "ideología de género" para poder designarlos, a partir de este único término, como "antinaturales" y peligrosos. La base de esta significación se puede rastrear, por lo menos, hasta las posturas de la Iglesia católica en los tiempos del papa Juan Pablo II, así como en las ideas impresas en encíclicas, exhortaciones evangélicas y diferentes publicaciones del pontífice y de sus allegados, en las cuales advertían acerca de los riesgos del "relativismo" moral y cultural (Vaggione, 2020, p. 255). Sin embargo, se sospecha que el término apareció por primera vez hasta 1997 asociado a dos documentos: el libro La agenda de género: redefiniendo la igualdad, que la periodista Dale O'Leary ${ }^{8}$ escribió como respuesta a la Conferencia Internacional sobre la Población de El Cairo (1994) y a la Conferencia Mundial sobre la Mujer de Beijing (1995), ${ }^{9} \mathrm{y}$ el prefacio del libro L'Évangile face au désordre mondial (1997) escrito por Joseph Ratzinger, quien posteriormente sería el papa Benedicto XVI (Mena López y Ramírez Aristizabal, 2018; Vaggione, 2020). Este último texto, en palabras de Vaggione (2020), "tuvo un rol central en la adopción, circulación y legitimación del término 'ideología de género"' (p. 256). ${ }^{10}$

Acompañando a estos antecedentes, la nueva ola de los fundamentalismos, que se ha expandido con particular fuerza en América Latina durante la última década, tiene características propias que es necesario tomar en cuenta para poder estudiarla y entenderla. Entre éstas se encuentra, por ejemplo, la vinculación entre iglesias católicas y evangélicas para impulsar iniciativas

7 Si bien a lo largo de este trabajo utilizamos el término "fundamentalismo" para referirnos a estos actores, muchos autores han cuestionado la terminología que se utiliza y han acuñado conceptos como "neoconservadurismo" o "neofundamentalismo" para caracterizar algunas de sus particularidades (véase Caro y Fediakova, 2000; de la Torre, 2020).

8 La estadounidense Dale O'Leary es conocida por haber sido miembro del Opus Dei, de la Asociación Médica Católica de Estados Unidos y de la Asociación Nacional para la Investigación y Terapia de la Homosexualidad, así como por sus escritos en contra del movimiento feminista de la época y a favor de las terapias de conversión (Mena López y Ramírez Aristizabal, 2018).

9 Durante la Conferencia Internacional sobre la Población de El Cairo (1994) y la Conferencia Mundial sobre la Mujer de Beijing (1995), diferentes derechos sexuales y reproductivos fueron reconocidos formalmente como parte de los derechos humanos (Vaggione, 2020).

10 Versión original en inglés: "Ratzinger [...] had a central role in the adoption, circulation, and legitimation of the term 'gender ideology". 
comunes; una estrategia sin precedentes que Nicolás Panotto denomina "ecumenismo de ofensiva moral" (2019, p. 22). Respecto a la politización evangélica actual dentro de dicho movimiento, Karina Bárcenas (2021, p. 130) identifica tres tipos de actores: religiosos, parlamentarios y de la sociedad civil interreligiosa; posicionados en tres escenarios distintos: el espacio público, el espacio legislativo y las redes socio digitales - estas estrategias también son utilizadas, cada vez más, por sectores católicos y otros grupos cristianos-.

En lo que concierne a los discursos que actualmente pregona el movimiento fundamentalista, Bárcenas (2021) señala que están cimentados en el pánico moral y la construcción de una posverdad en la cual "los hechos objetivos son menos influyentes para moldear la opinión pública que apelar a la emoción y la creencia personal" (p. 144). El propio término "ideología de género" es, en palabras de Margarita Sánchez (2020), "un saber-poder que tiene la intención de desacreditar y desarticular todo lo relacionado a los análisis de género" (p. 27) en un intento de presentarlos no como una corriente de producción de conocimiento interdisciplinaria, histórica y diversa sino como una "ideología", en un sentido de imposición o manipulación carente de sustento.

El impacto de dichas narrativas se encuentra en su capacidad de socializarse a través del miedo - "no te metas con mis hijos" es uno de los ejemplos más claros-. Sus discursos comienzan con la creación de un "otro" -las feministas, la comunidad LGBTIQ+-, luego se caracteriza esa "otredad" como un riesgo -ignorando que en la mayoría de los casos forman parte de sectores vulnerabilizados- y posteriormente se difunden argumentos que buscan legitimar las prácticas violentas en su contra, ya no como un ataque sino como una forma de defensa.

En el caso de la lucha por el aborto, esto se materializa en campañas mediáticas que presentan a las mujeres que abortan y a quienes las respaldan como asesinas, así como en la publicación de datos personales, la obstaculización del acceso al procedimiento de interrupción del embarazo, el hostigamiento a médicos que lo realizan o la exclusión de espacios de socialización y religiosos de mujeres creyentes que deciden interrumpir su embarazo.

\section{Acercamientos al aborto desde la fe cristiana y alternativas desde las teologías feministas}

Contrario a la pretensión de homogeneidad e inmutabilidad que los fundamentalismos religiosos suelen sostener, en muchas ocasiones las doctrinas que componen las posturas de las iglesias se han transformado e incluso 
borrado a lo largo de la historia. Teorías como la evolución biológica, que en un momento fueron rechazadas fervientemente por parte de las iglesias, ahora son aceptadas e incluso enseñadas en algunas escuelas cristianas. Los debates y posturas respecto a la interrupción del embarazo son un ejemplo aún más complejo de dichas transformaciones. A lo largo del tiempo, la visión de las iglesias respecto al aborto se ha transformado, diversificado e incluso contradicho. ${ }^{11}$

En gran medida, la pluralidad de opiniones alrededor del tema se debe a que en la Biblia el aborto - o el no aborto- prácticamente no se menciona. En el Antiguo Testamento, las alusiones o sugerencias son muy pocas ${ }^{12}$ y, en el Nuevo Testamento, Jesús no predica nada al respecto. Sumado a esto, la lectura y el estudio de la Biblia inevitablemente están acompañados de la inclinación personal y el contexto cultural de quien los realiza. ${ }^{13}$

La interrupción del embarazo es un tema complejo que ha sido estudiado y analizado desde diferentes posturas teológicas, las cuales han hecho su propia interpretación bíblica basadas en los pocos versículos que mencionan el tema. Entre éstas se encuentran las que han hecho las

11 La postura de San Agustín, padre de la Iglesia católica y santo por las Iglesias ortodoxa, oriental y anglicana, es una muestra clara de lo antes mencionado. Él pensaba que el aborto no podía ser considerado un asesinato porque no era posible que existiera un alma dentro de un cuerpo que no estuviera totalmente formado (Mejía Piñeros, 2019). Casi un milenio más tarde, Santo Tomás de Aquino continuaba respaldando esta afirmación (Roberto, 2018). Así como ellos, varios personajes remarcables en la historia del cristianismo han adoptado posturas diferentes a lo que ahora la "lucha en contra de la ideología de género" defiende como algo inamovible.

12 Entre estas alusiones se encuentra Éxodo 21:22-25, en donde se habla de lo que sucedería si en una riña alguna persona lastimara a una mujer embarazada y se perdiese al producto; la consecuencia de este acto sería determinado por el marido de la mujer pero, si llegase a morir la mujer, se pagaría vida por vida. En esta historia, el valor de la mujer no es el mismo que el del producto; la consecuencia es diferente y se prioriza la vida de ella. También se encuentra Números 5:11-31, en donde se habla de lo que sucedería si el espíritu de celos de un hombre viniera hacia su esposa. Él tenía que presentarla ante Jehová y ante el sacerdote para aplicarle una ley ritual en la que se le daba a beber aguas amargas; si la mujer resultaba responsable del engaño y quedaba embarazada, el agua provocaría que se cayesen sus órganos sexuales e induciría el aborto.

13 La Biblia no se puede utilizar en su totalidad para validar la posición acerca de la interrupción del embarazo o la autonomía sexual de las mujeres porque su lectura siempre estará impregnada de los motivos y el contexto de quien la lee, pero definitivamente puede ayudar a proporcionar recursos para dignificar a las mujeres y no culpabilizarlas (García Bachmann, 2018). 
disidencias cristianas feministas, quienes han demostrado estar abiertas a hacer nuevas interpretaciones de la fe que reivindiquen el derecho a la autonomía sexual y reproductiva, cuestionando así los límites establecidos por las iglesias institucionalizadas conservadoras con intenciones de crear espacios plurales y seguros para aquellas personas que históricamente han sido excluidas y menospreciadas.

Por décadas, los sectores fundamentalistas que consideran que la agenda que defienden es progresista y anticristiana han tratado de negar la identidad de las mujeres creyentes feministas. Un claro ejemplo del silenciamiento de las voces disidentes fue lo ocurrido en Brasil durante el mes de octubre de 2020, cuando, por determinación de la 2. ${ }^{a}$ Cámara de Derecho Privado del Tribunal de Justicia de San Pablo, se prohibió a la asociación Católicas pelo Direito de Decidir utilizar el término "católicas" en su nombre..$^{14}$ A pesar de la oposición, las mujeres creyentes hemos buscado formas de organizarnos y acompañarnos ante la violencia sistémica e institucional por parte de las distintas Iglesias cristianas. Las voces disidentes y sus métodos de acción continúan fortaleciéndose y dándonos pautas para la construcción de alternativas a los discursos y prácticas que en nombre de Dios niegan derechos y justifican la opresión.

Ejemplos de ello hay muchos. En los últimos quince años, diferentes organizaciones han publicado manuales para acompañar, con argumentos desde la fe, la decisión de interrumpir un embarazo, así como para apoyar a las y los cristianos que cuestionan el enfoque de los fundamentalismos religiosos. Entre estos manuales está el tríptico Libertad de conciencia y decisión, de Católicas por el Derecho a Decidir Perú, que presenta, a partir del Concilio Vaticano II, la libertad de conciencia y la profunda comunicación personal con Dios como parte necesaria de la fe cristiana; en él también se argumenta que toda mujer tiene la capacidad de tomar la decisión de interrumpir o no su embarazo a partir de su propia conciencia, sin necesitar de ninguna doctrina externa.

Por su parte, Católicas por el Derecho a Decidir México elaboró una serie de Hojas Informativas Dominicales en donde abordan diferentes

14 Para más información respecto al caso, así como para revisar la respuesta de la organización y la campaña de apoyo que recibieron en redes sociales, ver Florentin (2020) y Con efe (2020). 
aristas de la justicia reproductiva. Entre estas hojas informativas destaca el volumen número once, en el cual, después de explicar cada parte de la reforma legislativa que en 2007 despenalizó el aborto en la Ciudad de México, plasman una crítica a la jerarquía católica que se opone a la interrupción del embarazo y hacen notar que dicha oposición va en contra de la propuesta de caridad y libertad de Jesús:

Por su propio ejemplo, Jesús enseñó que la vida plena es más importante que las leyes y políticas religiosas, mostró respeto por todas las mujeres - aún las consideradas indeseables y las supuestamente impuras- y defendió el derecho de la mujer a tomar la decisión de romper un tabú. (Católicas por el Derecho a Decidir A. C. y Observatorio Eclesial, 2007, pp. 3-4)

Entre los volúmenes, también destaca el número trece, en el que, a partir del pasaje de la Anunciación a María (Lucas 1:26-38), se defiende el derecho a decidir: "Al ser María consultada podemos comprender que la divinidad pregunta, consulta, solicita, convoca, invita. No arrebata, no impone, no invade, no violenta la voluntad" (Católicas por el Derecho a Decidir A. C., 2008, p. 2). Aunque los sectores fundamentalistas han intentado apropiarse de esta historia de María para defender "el sí a la vida", muchas mujeres cristianas creemos que ese momento de elección es un recordatorio de que la autonomía sexual, reproductiva y de elección es un derecho humano de todas las mujeres.

Aunado a las hojas informativas previamente mencionadas, Católicas por el Derecho a Decidir México publicó en 2019 el cuadernillo Interrupción del embarazo: algunas reflexiones para tomar decisiones éticas. En éste se responden preguntas que "surgen de dudas profundamente humanas que causan dolor y preocupación a algunas mujeres católicas [y algunas mujeres cristianas] antes, durante y después de haber interrumpido su embarazo" (Católicas por el Derecho a Decidir A. C., 2019, p. 3).

Con una estructura y finalidad similar, María López Vigil publicó en 2008 el cuadernillo ¿Interrumpir el embarazo es pecado? ¿Cómo decidir ante Dios y en conciencia? En este texto, la autora reflexiona alrededor de cuestionamientos difíciles como el dilema entre la vida y la muerte, la responsabilidad sobre nuestra vida y nuestra libertad, el alma humana, la confianza en las mujeres, entre otros. 
También, entre los cuadernillos de esta variedad, nos parece importante mencionar A destapar los mitos del movimiento "Pro-Vida" de Soulforce (2021), en el cual se analizan aseveraciones como: "La voluntad de Dios es que todos los embarazos se lleven a término", "Los fetos deben tener los mismos derechos que las personas embarazadas", "La vida comienza en el momento de la concepción", "Las personas cristianas no abortan" o "Defender el derecho a decidir es estar en contra de la familia", y se contra argumenta cada una de ellas con base en la Biblia, la historia de las Iglesias y estadísticas sobre el aborto en Estados Unidos.

De manera paralela a la escritura de los antedichos manuales, mujeres y disidencias cristianas a lo largo de Latinoamérica han formado colectivas que activamente buscan el avance de los derechos sexuales y reproductivos. En su libro Las teologías feministas frente al fundamentalismo religioso, la Red de Teólogas, Pastoras, Lideresas y Activistas Cristianas (Red TEPALI, 2020) realiza una sistematización de algunos de esos esfuerzos a lo largo del continente que, si bien están situados en contextos específicos, dejan en claro que la articulación entre mujeres es nuestra herramienta más poderosa para contrarrestar los embates conservadores. Ya sea acompañando física, emocional, pastoral y jurídicamente a mujeres que deciden interrumpir su embarazo en un contexto violento y profundamente afectado por un golpe militar, como es el caso de las Ecuménicas por el Derecho a Decidir en Honduras; uniendo fuerzas con decenas de teólogas feministas, pastoras, pastores, obispos y personas laicas activistas para defender el aborto legal con argumentos bíblicos, teológicos y pastorales tanto en el Congreso como en las calles, como lo hicieron las compañeras argentinas desde el surgimiento de la Campaña Nacional por el Derecho al Aborto Legal, Seguro y Gratuito en 2005 y hasta su victoria en 2020, o haciéndole frente desde las iglesias, academia y sociedad civil a un presidente que ha excusado con Biblia en mano la violación de mujeres y el asesinato de personas de la diversidad sexo genérica, como lo hacen nuestras hermanas brasileñas... juntas resistimos.

\section{Repensar, fortalecer y defender la laicidad}

Como lo señalamos antes, las visiones de laicidad que se basan en la negación de lo religioso en el espacio público demuestran una comprensión reduccionista del fenómeno religioso en las sociedades latinoamericanas. Además, como lo han hecho notar las feministas islámicas (Asad, 2003; 
Adlbi Sibai, 2016) y académicas como Joan Wallach Scott (2020), ${ }_{15}^{15}$ las posturas que presentan la secularización ${ }^{16}$ como ideal y único horizonte posible para la construcción de sociedades comprometidas con los derechos humanos poco toman en cuenta que este modelo sustenta un orden eurocéntrico y colonial y también reproduce asimetrías de género en donde el Estado sustituye a la religión para adquirir el control de la sexualidad femenina, relegando a las mujeres a la esfera privada al considerarlas ciudadanas de segunda categoría.

La configuración política del poder, históricamente, era legitimada por la religión, pero, en la modernidad, es el Estado quien ocupa el lugar de autoridad soberana. Es decir que el Estado, para asegurar este dominio, ha tratado de hacer de la religión un objeto de experiencia privada y personal basándose en una supuesta racionalidad objetiva que le ha limitado comprender y atender la diversidad de experiencias humanas. Al contrario de los postulados de contención, las confesiones religiosas en América Latina han encontrado diferentes formas de mantenerse vigentes, instrumentalizarse y fortalecerse. De esta forma, creemos importante que a nivel gubernamental y académico se tome en consideración a los actores religiosos que participan políticamente y así evitar el avance de los fundamentalismos religiosos que vulneran los derechos humanos.

Esto no significa que debemos quitar de nuestra agenda la lucha por la laicidad; al contrario. Ésta, entendida como el principio de autonomía del Estado frente a autoridades o creencias dogmáticas, es indispensable para crear condiciones de igualdad a través de instituciones, normas y políticas públicas que favorezcan los derechos humanos y por consiguiente los derechos sexuales y reproductivos. Entender las complejidades que se le presentan a partir de las tensiones ya abordadas en este trabajo es fundamental para fortalecer sus marcos de acción y construir estrategias para defenderla.

15 Para una perspectiva comparada entre estas autoras, véase Meza Torres (2021).

16 Consideramos importante aclarar que, si bien van de la mano, secularización y laicidad no son lo mismo. La primera se refiere a un proceso social de "pérdida de centralidad de la esfera religiosa en la organización social", mientras que la segunda en términos generales describe al régimen jurídico que posibilita "la autonomía del aparato estatal, sus instituciones, sus autoridades y sus normas respecto de toda creencia dogmática, sea religiosa o no" (Católicas por el Derecho a Decidir A. C. y Cátedra Extraordinaria "Benito Juárez", 2020). 
El establecimiento de una sociedad democrática requiere modelos de laicidad cimentados en el reconocimiento del pluralismo religioso - entendiéndolo no como el simple reconocimiento de la diversidad religiosa como una característica de una sociedad o su grado de aceptación dentro de ella, sino como la efectiva valoración de dicha diversidad en términos morales y políticos (de la Torre y Semán, 2021, p. 38)-, lo cual debe fundamentarse siempre en el ejercicio de los derechos humanos. De acuerdo con Católicas por el Derecho a Decidir A. C. y la Cátedra Extraordinaria "Benito Juárez" (2002), "el Estado laico tiene una vocación contramayoritaria; es decir, busca proteger a los grupos minoritarios ante la imposición de las posturas y valores de las mayorías" (p. 3). Esto significa que la laicidad es una condición necesaria para la consolidación de una sociedad democrática no porque busque priorizar la voz de la mayoría, sino porque permite la participación política de todos sus actores en igualdad de condiciones, sin verdades absolutas que impongan jerarquías entre distintas posturas e identidades.

El reto de monitorear la laicidad es profundamente complejo por muchos motivos, entre los cuales está la diversidad de acercamientos al tema en cada país. Ésta, al ser fruto de procesos históricos en contextos diferenciados, ha pasado por distintas etapas y hasta la fecha continúa en evolución. Un ejercicio que nos parece importante de socializar y estudiar fue el realizado por Católicas por el Derecho a Decidir A. C. y la Cátedra Extraordinaria "Benito Juárez" (2020) en su Informe sobre laicidad y derechos reproductivos y sexuales en América Latina y el Caribe. En él, se examinan los marcos jurídicos de cada país de la región y las políticas públicas en materia de derechos sexuales y reproductivos que se han implementado en cada uno. Tras un exhaustivo análisis, las organizaciones realizan una serie de recomendaciones dirigidas a personas en puestos de toma de decisiones, feministas y personas defensoras de derechos humanos. Si bien recomendamos a quienes nos leen que revisen este documento a profundidad, compartimos a continuación los cuatro ejes en los que se dividen dichas recomendaciones:

1. La responsabilidad de los Estados de resguardar los principios laicos que se establecen en sus marcos legales.

2. La necesidad de impulsar estrategias de protección y defensa de la laicidad desde la sociedad civil organizada -el informe enlista algunas propuestas-. 
3. La construcción de una agenda laica a partir de la creación y el fortalecimiento de alianzas entre academia, activistas y organizaciones.

4. El monitoreo constante y la denuncia pública de las violaciones a la laicidad del Estado por parte de actores públicos y privados.

En la actualidad, existen limitaciones teóricas y prácticas entre los modelos de laicidad y las dicotomías de la condición ciudadana y espiritual que necesitan ser resueltas para garantizar los derechos humanos de aquellas personas que tengan creencias y valores distintos a la cultura predominantemente socializada; es necesario reconocer que las personas creyentes tienen un lugar en la esfera pública y no sólo en la privada y, a la vez, no subestimar la influencia que pueden llegar a tener como colectividad.

\section{Conclusiones}

Históricamente, las Iglesias cristianas han sido espacios de organización de movimientos en contra de los derechos de las mujeres, ejerciendo sobre nosotras violencia discursiva, física y psicológica, lo cual ha llevado a que, en muchas ocasiones, el movimiento feminista busque eliminar a la religión de las discusiones respecto a la justicia reproductiva.

Sin embargo, no se puede menospreciar la influencia que el cristianismo tiene en el mundo social - tanto en el ámbito público como en el privado- pues el subestimarla ha provocado que las organizaciones antiderechos fortalezcan y visibilicen su agenda conservadora que perpetúa la desigualdad.

A lo largo de este escrito hemos compartido algunos aportes que -desde nuestra experiencia como mujeres jóvenes, creyentes, feministas y acompañantes de procesos de aborto, y como mujeres que, a la par, han experimentado muy de cerca los discursos acerca de la "ideología de género" y sus consecuencias- consideramos que pueden nutrir los espacios de reflexión y activismo en materia de derechos humanos - particularmente derechos sexuales y reproductivos- y fortalecer la lucha en contra de los fundamentalismos religiosos.

En primer lugar, presentamos nuestro trabajo como colectiva y nuestras razones para incluir la fe en nuestras conversaciones respecto al derecho a decidir. Compartimos algunas de nuestras observaciones acerca de las identidades creyentes y el papel que, en muchos casos, toma la fe en los procesos de quienes deciden interrumpir su embarazo. Además de 
ello, señalamos la necesidad de que dentro de los espacios de activismo se profundice en la conversación respecto al fenómeno religioso y sus nuevas configuraciones dentro del espacio público, dejando a un lado prejuicios y caricaturizaciones para dar pie a reflexiones complejas que, sin dar ningún paso atrás en materia de derechos para colectividades históricamente vulnerabilizadas, cuestionen los modelos tradicionales que presentan la diversidad de creencias como un problema que puede y debe quedarse en el ámbito de lo privado.

Más adelante abordamos el fenómeno de los fundamentalismos religiosos. Realizamos una pequeña cronología de su surgimiento, subrayando las características que se han transformado con el tiempo y aquéllas que continúan siendo importantes hoy en día dentro de la llamada "lucha en contra de la ideología de género"; remarcamos que conocer sus discursos y mecanismos de acción (además de los razonamientos detrás de éstos) es prioritario si buscamos hacerles frente.

En ese sentido, dedicamos un apartado de nuestro trabajo a visibilizar colectivos y organizaciones que luchan desde la fe por los derechos sexuales y reproductivos de las mujeres, así como recursos teológicos que a través de la reinterpretación de textos bíblicos construyen narrativas alternas a aquéllas que se han proclamado como hegemónicas dentro de las comunidades religiosas. Familiarizarnos con estas lecturas liberadoras nos parece especialmente importante porque creemos que, como señala Nicolás Panotto (2019), "la manera más efectiva de contrarrestar dichas avanzadas es utilizar sus mismos marcos de sentido y discursivos, es decir, cosmovisiones religiosas y teológicas" y coincidimos con su planteamiento de que "la denuncia solo en términos de discriminación, aunque válidos, lo único que hace es fomentar el sentido de heroísmo y mesianismo presente en estos grupos".

Finalmente, compartimos algunas de nuestras reflexiones respecto a limitaciones teóricas y prácticas de ciertos modelos tradicionales de laicidad; proporcionamos algunos recursos que, a nuestro parecer, pueden abonar a la construcción de nuevas laicidades que tomen en cuenta el papel de la religión dentro de la construcción de las identidades de los sujetos y fomenten el diálogo crítico intercultural en un marco de derechos humanos.

Esperamos que los aprendizajes vertidos en estas páginas puedan ser retomados por compañeras feministas no creyentes en sus espacios de or- 
ganización y que desencadenen procesos de reflexión y articulación que fortalezcan nuestras acciones de defensa del derecho a decidir. De igual manera, esperamos compartir el texto con mujeres creyentes que estén en el camino de cuestionar y buscar otras formas de aproximarse al aborto, sin sentirse obligadas a renunciar a su identidad religiosa, para que conozcan que hay espacios de acompañamiento feminista que las abrazan y comparten con ellas su amor a Jesús.

\section{Referencias bibliográficas}

Adlbi Sibai, S. (2016). La cárcel del feminismo. Hacia un pensamiento islámico decolonial. Akal.

Angola, V. (2021, 27 de enero). Más allá del aborto, pensemos en justicia reproductiva. Malvestida. https://malvestida.com/2021/01/ mas-alla-del-aborto-pensemos-en-justicia-reproductiva/

Asad, T. (2003). Formations of the Secular: Christianity, Islam, Modernity. Stanford University Press.

Ávila González, Y. (2018). ¿Quién le teme al género? La lucha por el poder interpretativo. En C. Garma, M. Ramírez y A. Corpus. Familias, Iglesias y Estado laico: Enfoques antropológicos (pp. 69-78). Universidad Autónoma Metropolitana, Unidad Iztapalapa.

Bárcenas Barajas, K. (2021). La violencia simbólica en el discurso sobre la "ideología de género": Una perspectiva desde la dominación simbólica a través del pánico moral y la post-verdad. Intersticios sociales, (21), 125-150.

Caro, I. y Fediakova, E. (2000). Los fundamentalismos religiosos: Etapas y contextos de surgimiento. Fermentum. Revista Venezolana de Sociología y Antropología, 10(29), 453-467.

Católicas por el Derecho a Decidir A. C. (2019). Interrupción del embarazo: Algunas reflexiones para tomar decisiones éticas. http://catolicasmexico.org/i/wp-content/uploads/2020/09/interrupcionembarazoWEB_24septiembre2020.pdf

Católicas por el Derecho a Decidir A. C. (2008). María fue consultada para ser madre de Dios. Elegir es un derecho de todas. Libertad de conciencia. Hoja informativa dominical, (13). http://catolicasmexico. org/i/wp-content/uploads/2020/02/8-Libertad-de-conciencia-Maria-fue-consultada-para-ser-madre-de-Dios.pdf

Católicas por el Derecho a Decidir A. C. y Cátedra Extraordinaria "Benito 
Juárez" (2020). Informe sobre laicidad y derechos reproductivos $y$ sexuales en América Latina y el Caribe. Católicas por el Derecho a Decidir A. C. http://catedra-laicidad.unam.mx/sites/default/files/ Laicidad\%20Informe\%20DSR.pdf

Católicas por el Derecho a Decidir A. C. y Observatorio Eclesial (2007). Aborto: Aspectos sociales, legales, éticos y religiosos. Invitación al debate. Libertad de conciencia. Hoja informativa dominical, (11). http://catolicasmexico.org/i/wp-content/uploads/2020/02/9-Libertad-de-conciencia-Aborto-Aspectos-sociales.pdf

Católicas por el Derecho a Decidir Perú (2012). Libertad de conciencia y decisión: Derechos fundamentales para construir y ejercer ciudadanía. https://cddperu.org/sites/default/files/libertad_conciencia_ok.pdf Clansi, R. (2021, 17 de mayo). Yuderkys Espinosa: El feminismo (blanco) es un programa totalmente moderno y si es moderno es racista. Revista La Brújula. https://revistalabrujula.com/2021/05/17/yuderkys-espinosa-el-feminismo-blanco-es-un-programa-totalmente-moderno-y-si-es-moderno-es-racista/

Con efe (2020, 29 de octubre). Prohibición de uso del término "católica" lleva a mujeres a afirmar "Somos católicas y somos muchas". https:// www.conefe.net/noticias/prohibicin-del-uso-del-trmino-catlica-lleva-a-mujeres-a-afirmar-somos-catlicas-y-somos-muchas

Davis, A. (2005). Mujeres, raza y clase. Akal.

Florentin, C. (2020, 28 de octubre). Tribunal de Justicia prohíbe a Católicas por el Derecho a Decidir Brasil usar "católicas" en el nombre. Agencia Ecuménica de comunicación. https://alc-noticias.net/es/2020/10/28/ tribunal-de-justicia-prohibe-a-catolicas-por-el-derecho-a-decidir-brasil-usar-catolicas-en-el-nombre/

García Bachmann, M. L. (2018). Reflexión sobre la legalización del aborto desde una perspectiva bíblica, luterana y feminista. Iglesia Evangélica Luterana. http://ielu.org/wordpress/wp-content/uploads/2018/07/Garc\%C3\%ADa-Bachmann-Reflexión-sobre-el-aborto-en-la-Biblia.pdf

Garma, C. (2018). Conversión y movilidad religiosa, propuesta para su análisis. Revista Cultura y Representaciones Sociales, 12(24), 97-130.

Instituto Nacional de Estadística, Geografía e Informática (2020). Tabulados interactivos. https://www.inegi.org.mx/programas/ccpv/2020/\#Tabulados

López Vigil, M. (2008). ¿Interrumpir el embarazo es pecado? ¿Cómo decidir 
ante Dios y en conciencia? Copy Express S. A. https://www.corteidh. or.cr/tablas/28965.pdf

Mejía Piñeros, M. C. (2019). Interrupción del embarazo: Algunas reflexiones para tomar decisiones éticas. Católicas por el Derecho a Decidir A. C. http://catolicasmexico.org/i/wp-content/uploads/2020/09/interrupcionembarazoWEB_24septiembre2020.pdf

Mena López, M. y Ramírez Aristizabal, F. M. (2018). Falacias discursivas en torno a la ideología de género. ex æquo, (37), 19-31. https://exaequo. apem-estudos.org/artigo/las-falacias-discursivas-en-torno-a-la-ideologia-de-genero

Meza Torres, A. (2021). La secularización como un discurso de "misión": Una mirada desde el feminismo crítico y los feminismos descoloniales. Interdisciplina, 9(24), 145-171.

Panotto, N. (2019). Fe que se hace pública: Reflexiones sobre religión, cultura, sociedad e incidencia. Juanuno1 Ediciones.

Pérez Cruz, O. (2017). Fundamentalismos y prosperidad: Trump y su "Make America Great Again". En M. A. Gandásegui y J. A. Preciado Coronado (eds.), Hegemonía y democracia en disputa: Trump y la geopolítica del neoconservadurismo (pp. 189-218). CLACSO. https://doi. org/10.2307/j.ctvtxw3c5.11

Red de Teólogas, Pastoras, Lideresas y Activistas Cristianas (2020). Las teologías feministas frente al fundamentalismo religioso. Unida.

Roberto, M. A. (2018). Estado e Iglesias frente a la despenalización y legalización del aborto. En N. Panotto y C. Florentin (eds.), Dossier: Estado laico y pluralismo religioso en Argentina. Agencia Latinoamericana y Caribeña de Comunicación, Grupo de Estudios Multidisciplinarios sobre Religión e Incidencia Pública. https://www.otroscruces.org/ wp-content/uploads/2018/10/Articulo-Mar\%C3\%ADa-de-los-Angeles-Dossier-.pdf

Sánchez, M. (2020). Las tumbas vacías. Oikodomein, 24(19), 25-30.

Scott, J. W. (2020). Sexo y secularismo. Universidad Nacional Autónoma de México, Centro de Investigaciones y Estudios de Género; El Colegio de México, Programa Interdisciplinario de Estudios de Género.

Soulforce (2021). A destapar los mitos del movimiento "Pro-Vida". https:// www.soulforce.org/mitos-pro-vida

Tamayo, J. J. (2009). Fundamentalismos y diálogo entre religiones. Trotta.

Torre, R. de la y Semán, P. (2021). Introducción: Religiones y espacios 
públicos en América Latina. En Religiones y espacios públicos en América Latina (pp. 11-51). CLACSO.

Vaggione, J. M. (2020). The conservative uses of law: The catholic mobilization against gender ideology. Social Compass, 67(2), 252-266. https:// doi.org/10.1177/0037768620907561

Vaggione, J. M. (2005). Reactive politicization and religious dissidence. The political mutations of the religious in social theory and practice. Social Theory and Practice, 31(2), 233-255.

Vuola, E. (2001). God and the government: Women, religion, and reproduction in Nicaragua [ponencia]. XXIII International Congress of the Latin American Studies Association (LASA 2001), Washington, DC. https:// citeseerx.ist.psu.edu/viewdoc/download?doi=10.1.1.556.4867\&re$\mathrm{p}=$ rep1\&type=pdf 